\title{
Application of Green Building Materials in Civil Engineering Construction
}

\author{
Zhou Jia-yao $^{1}$ \\ ${ }^{1}$ School of Management, 300000, Tianjin University of Technology, Tianjin, China
}

\begin{abstract}
The continuous economic and social progress of our country has helped the rapid progress of civil engineering projects. However, the relatively improved civil engineering project creation also has many shortcomings, such as waste of resources, depletion, and pollution of the natural environment. The construction project itself is an item. The energy consumption is relatively high. Due to the shortage of resources and the more serious natural environment and ecological problems, the public pays more attention to the related problems of their own quality of life, and more and more people are adopting green building materials. Therefore, it is very important to explore the application of green building materials in civil engineering projects.
\end{abstract}

\section{Characteristics of green building}

\subsection{Characteristics of green building materials}

Green building materials have five characteristics in terms of definition: Second, green building materials consume less energy and produce less waste. Under normal circumstances, green building materials have extremely high technological means. It is produced; secondly, in the creation of civil engineering projects, green building materials can effectively reduce its resource loss. In the creation of civil engineering projects today, most of the new materials have the characteristics of waterproof, low quality and strong ability. , In the creation of reality, it can effectively reduce the loss that occurs in the transportation practice. Third, the quality of green and environmentally friendly building materials is better than that of previous building materials. For example, the concrete that is often used today has the characteristics of light weight and high quality. Fourth, green building materials can efficiently optimize indoor air quality and improve living spaces. Fifth, most of the green building materials are the recycling and reuse of those garbage, which saves resources and reduces the damage to the natural ecological environment. Based on this, it is of great benefit to the daily life of the public that green materials can be obtained. In the creation of civil engineering projects, it is necessary to use green materials as much as possible to help the longterm progress of the construction field.

\subsection{The importance of green building materials in civil engineering construction}

The key to green materials is fundamentally shown in the following perspectives: it can meet the requirements of consumers. The rapid economic and social improvement of our country has helped the progress of the construction field, but in this practice, great environmental and ecological damage and energy consumption have also appeared. Due to the continuous improvement of the public's environmental protection thinking, environmental protection and green engineering thinking are gradually valued in the construction field. Zeng Yao uses available energy efficiently, reduces energy damage, and helps the ecological environment to develop steadily. These phenomena have become the most important points of the public today. Under such a premise, the public has a stricter need for building materials used in the construction field, and the emergence of green materials meets the public's need for living space. In addition, it effectively controls environmental pollution. Green and environmentally friendly materials are a key step to complete the long-term progress strategy.

\section{Application of green building materials in civil engineering}

\subsection{The use of green building materials in top-end design}

In the top-end design work of civil engineering projects, green materials for environmental protection are widely used because of its own advantages. However, in the actual creation, the correct and appropriate use of materials should also be implemented in accordance with the operating conditions of the project, and then the greater benefits of materials should be shown. First of all, there must be clear indicators in the selection of materials. The styles and needs of materials used in the implementation of the project should be clearly pointed out; materials should be selected correctly to ensure that the effects of

\footnotetext{
* Corresponding author: Zhou Jia-yao 1761551937@163.com
} 
materials are better displayed. For example, in high-level operations, the top design should fully consider the needs of urban planning and architecture majors, whether the top design is smooth, whether it is diversified, and so on. From the perspective of urban planning, the appearance of the top design in the entire urban space has a more prominent meaning, and the green environmental building materials can better show the meaning of technological creation (for example, [1]) Secondly, in actual operations, green building materials and implementation methods should be organically integrated. Nowadays, the volume of civil engineering projects is very large, and the scope is getting bigger and bigger. Due to the progress in the construction field, some new methods and new processes have also been explored. The efficient integration of scientific and technological innovation and new methods can show green building materials. Need to show the effect, while achieving beautiful results.

\subsection{Use of green building materials in external design}

In engineering projects, from external implementation to internal implementation and then to installation and repair, the construction span is often very large, and the amount covered is also very large. Due to the continuous improvement of Volkswagen's environmental protection and green thinking, green building materials are widely used in the actual operation of engineering projects. In the external work of buildings, green building materials have fundamentally the effect of heat preservation and heat insulation, which not only saves resource loss efficiently, but also enhances the ornamentation of the building (for example, [2]) The difference between green construction and traditional construction is shown in Table 1 Show.

Table1 Differences between green and traditional construction

Traditional construction

Take cost, quality, safety, and construction period as the main control indicators

Project indicator level

Achieve construction target requirements at the lowest cost

Project overall

objective level

Project management level

Stakeholder target level
Stakeholders all take to maximize their own economic benefits as their main goal, and the organizations restrain each other.
Green construction

On the basis of the traditional construction control index.

The environment and saving resources, cost savings not violate the requirements of green construction indicators.

Green construction pay more attention to the effective transmission of information.

Economic and social benefits are equally important. Stakeholders need to form a benefit-sharing alliance through collaboration.
From the perspective of building thermal insulation, most of the green building materials have this function, and they are used in civil engineering projects to deeply improve the quality of life of the general public(for example, [3]). The efficient use of thermal insulation building materials can reduce the public's use of air conditioning, and has a key effect on creating an ecological natural environment. In addition, green building materials can also achieve the effect of shielding radiation and improve the earthquake resistance of buildings(for example, [4]). Green and environmentally friendly building materials have relatively large technical components, which can complete the recycling and reuse of garbage.

\subsection{The use of green building materials in the interior decoration industry}

With the improvement of the quality of life of the general public, the standard for buildings is not only a blind rest function, but also meets the needs of the public's spiritual level, which should be both beautiful and comfortable. The previous building decoration materials are extremely harmful to the human body, and are also restricted by the weight of the materials themselves. The effect shown in interior decoration operations is very small, but the green building materials can effectively improve this part of the shortcomings. In terms of the degree of restraint, green environmental building materials have their unique strengths, for example, heat insulation and noise reduction, 
etc., which contribute feasible factors for the public to avoid external disturbances(for example, [5]).

\section{Issues that should be paid attention to in the construction of civil engineering using green building materials}

\subsection{Issues that need attention in the selection of green building materials}

Under normal circumstances, the scope of civil engineering projects is very large, and many building materials will be used. When implementing the selection of building materials, we should not only consider the needs of cost and quality, but also consider whether the materials can be used to achieve the expected results. In addition, according to the progress and implementation of the project, the correct selection of environmentally friendly materials should be implemented so that the green environmentally friendly building materials can show the effects that they should play in the civil engineering project, and avoid the occurrence of improper selection of materials. The resulting quality problems.

\subsection{Issues that need attention in the construction of green building materials}

Green and environmentally friendly materials are the use of high-tech methods to process and improve waste and then use high-absorption ground to reduce resource loss. There are also rich styles of green and environmentally friendly building materials that can meet the needs of the construction field and ensure long-term progress in the construction field. Finally, the construction field is one of our country's key economic supports. The implementation and use of green building materials in civil construction operations can help optimize our country's economic structure.

\section{Application of energy-saving, green and environment-friendly materials in construction engineering}

\subsection{Application of daylighting technology and heat insulation technology}

Modern construction projects have high requirements for daylighting technology and heat insulation technology, which is also an important part of the concept of energy saving and environmental protection. Use energy-saving green environmental protection materials for construction, so that the main body of the building can make full use of natural light and save power. Combining daylighting technology into energy-saving technology, the conversion of light energy into heat energy, or into electric energy after technical treatment, not only effectively saves resources, but also improves the level of environmental protection, which promotes the sound development of construction enterprises.

\subsection{Application of Green Glass}

The green glass used in construction engineering mainly includes foam glass, vacuum glass and low-emissivity coated glass. The main material of foam glass is material rich in glass phase or discarded glass. After adding modifier to these materials, adding a certain proportion of foaming agent and accelerator as needed, a new type of mixture will be formed. After melting and foaming, the glass material will be formed. Foam glass has very good corrosion resistance and good flame retardant effect, its thermal conductivity is low, and its density is small. If the building needs to have thermal insulation function, such as the construction of cold storage, you can use this kind of glass, and can obtain a certain sound absorption effect, which is more suitable for high-rise buildings. The energy saving and environmental protection advantages of vacuum glass are very obvious, which can eliminate the conduction heat transfer effect and the flow heat transfer effect generated by the gas. The use of this glass can obtain a very good thermal insulation effect. Low-E coated glass can reflect far infrared rays, and European and American countries have begun to use this glass at the end of the 20th century.

\subsection{Application of environmentally friendly exterior wall thermal insulation materials}

Polystyrene foam has the advantages of low thermal conductivity and low density, as well as very good thermal insulation and thermal insulation properties. Polystyrene foam has a uniform structure and high accuracy, but this material is easy to soften in a high-temperature environment, so it cannot exert fire resistance. If the building has higher requirements for fire resistance, this material cannot be used. Rock wool has high stability and reliability, and good fire resistance. The main material is diabase or basalt, and auxiliary materials are added to it and melted in a high temperature environment to make artificial inorganic fibers. The application of rock wool in construction projects can play a role in heat preservation and heat insulation, with strong tensile and compression resistance, sound insulation and air permeability. The outer wall of the building uses thermal insulation rock wool board, which has good thermal insulation effect and thermal insulation performance, and good results can be obtained.

\section{Conclusion}

Due to the improvement of green building materials and its manufacturing techniques, the use and progress of green building materials have become a must. However, many aspects of this type of materials should be considered in practice to ensure the quality of green materials. The strengths are fully demonstrated, helping the progress of the construction field.

\section{References}

1. J. Zuo, Z.-Y. Zhao,Environment and Planning B: 
Planning and Design . 30 (2014)

2. B. Mattoni, C. Guattari, L. Evangelisti, F. Bisegna, P. Gori, F. Renew Sustain Energy Rev, 82 (2018)

3. J. Zuo, S. Pullen, R. Rameezdeen, H. Bennetts, Y. Wang, G. Mao, et al. Renew Sustain Energy Rev, 70 (2017)

4. J. Liang, Y. Qiu, M. Resour Conserv Recycl, 141 (2019)

5. Z. Gou, X. Xie J Clean Prod, 153 (2017) 